\title{
Çocuk Sağlığı ve Hastalıkları Doktorlarının Empati Becerisi Üzerine Bir Pilot Çalışma*
}

\author{
A Pilot Study on Empathy Skills of Pediatrics \\ Selda Okuyazi, Meltem Direkii, Oya Ögenleriii, Didem Derici Yıldırım ${ }^{\text {iv }}$ \\ ' Dr.Öğr.Üyesi, Mersin Üniversitesi Tıp Fakültesi Tıp Tarihi ve Etik AD, https://orcid.org/0000-0002-5048-8679
}

iSBÜ Van Eğitim ve Araştırma Hastanesi, Çocuk Sağlığı ve Hastalıkları ve Çocuk Nörolojisi, https://orcid.org/0000-0003-1815-7981

iiiDoç.Dr. Mersin Üniversitesi Tıp Fakültesi Tıp Tarihi ve Etik AD, https://orcid.org/0000-0002-5118-6170

ivDr.Öğr.Üyesi, Mersin Üniversitesi Tıp Fakültesi Biyoistatistik ve Tıbbi Bilişim AD, https://orcid.org/0000-0001-7709-6133

öz

Giriş: Kendini duygu ve düşüncede bir başkasının yerine koyabilme olarak tanımlanan empati (duygudaşlık), hasta hekim ilişkisi bakımından önemlidir. Çocuk hastalıkları ve sağlığı hekimlerinin empati becerileri hasta yakınlarının en değerli varlıkları olan çocuklarının sağıı̆ı söz konusu olduğunda ön plana çıkar.

Amaç: Bu pilot çalışmanın amacı Mersin'deki bir hastanede çocuk sağlığı ve hastalıkları alanında görev yapan hekimlerin empati becerilerini ve bu beceriyi etkileyen faktörleri tespit etmektir.

Gereç ve Yöntem: Araştırmamız çocuk sağlığı ve hastalıkları alanında görev yapan hekimler üzerinde yürütülmüştür. Veri toplama formunun birinci bölümünde hekimlerin demografik özelliklerine yönelik sorular, ikinci bölümünde ise "Jefferson Empati Skalası" bulunmaktadır. Verilerin analizinde istatistik program olarak Statistica 13.3 kullanılmıştır.

Bulgular: Çalışmaya katılan 55 (26 erkek, 29 kadın) hekimin yaş ortalamaları 34,11 $\pm 6,99^{\prime}$ dir. Katılımcıların 6'sı (\%10,9) profesör, 2'si $(\% 3,6)$ doçent, 5'i $(\% 9,1)$ Dr. öğretim üyesi, 1'i $(\% 1,8)$ yan dal uzmanı, 10'u $(\% 18,2)$ yandal asistanı, 31'i $(\% 56,4)$ asistan hekimdir. Katılımcıların toplam puan ortalaması $98.42 \pm 12.71^{\prime}$ dür.

Sonuç: Çalışmamızda katılımcıların Jefferson Empati Skalasından aldıkları toplam puan ortalamasının, ortanın üzerinde olması olumlu bir durumdur. Bu pilot çalışmaya göre empati becerisini etkileyen faktörleri ortaya çıkaracak, olumlu yönleri pekiştirecek çalışmaların artırılması düşünülmektedir.

Anahtar Kelimeler: Empati, çocuk sağlığı ve hastalıkları uzmanı, asistan hekim, hasta hekim ilişkisi

\section{ABSTRACT}

Introduction: "Empathy" is a term that stands for the ability of a person to replace himself/herself in terms of emotion and thought with another individual. Empathy is essentially important particularly in the patient-physician relationship in the field of health. Pediatricians' empathy skills stand out when the matter is the health of children who are the most precious wealth of their parents. Aim: The objective of this pilot study is to identify the empathy skills of physicians dealing with pediatric disorders and to specify the factors affecting these skills in a hospital in Mersin.

Materials and methods: This study was conducted on physicians working in the field of child health and diseases. The data collection form consists of two parts; in the first part there are questions about the demographic characteristics of physicians and in the second part there is the "Jefferson empathy scale". All the analysis for evaluated using Statistica 13.3.

Results: The average age of 55 ( 26 male and 29 female) physicians was $34.11 \pm 6.99$. The average age of 55 ( 26 male and 29 female) physicians was $34.11 \pm 6.99$ years. $6(10.9 \%)$ of the participants were professors, $2(3.6 \%)$ associate professors, 5 (9.1\%) assistant professors, 1 (1.8\%) sub-branch expert, 10 (18.2\%) sub-branch assistant physicians, $31(56.4 \%)$ assistant physicians. The average of the total score of the participants was $98.42 \pm 12.71$.

Conclusion: In our study, the averages of the participants were higher than the intermediate level and this is a positive situation. According to the data obtained in this pilot study, it is thought to increase the studies to improve the positive aspects, which will reveal the factors affecting empathy skill.

Key words: Empathy, pediatrics, assistant physicians, patient- physician relationship

*Lokman Hekim Dergisi, 2019; 9 (2): 228-235

DOI: 10.31020/mutftd.552907

e-ISSN: $1309-8004$

Geliş Tarihi - Received: 12 Nisan 2019; Kabul Tarihi - Accepted: 25 Nisan 2019

Iletişim - Correspondence Author: Selda Okuyaz <okuyazs@gmail.com> 


\section{Giriş}

Kendini duygu ve düşüncede bir başkasının yerine koyabilme olarak tanımlanan empati, zaman içinde farklılık gösterebilir. ${ }^{1,2}$ On dokuzuncu yüzyıl sonunda insanın bir sanat eserinden nasıl etkilendiğini açıklama amacıyla kullanılan Almanca "Einfühlung" kelimesi empatinin kökenini oluşturmaktadır ve sonrasında bu kelime kişiler arasındaki anlayışı açıklama amacıyla kullanılır oldu. ${ }^{2}$ ingilizce olarak türetilen empati kelimesi hissetmek, başkalarının inançlarını ve niyetlerini anlayabilmek için onun içinde bulunduğu durumu düşünebilmesi anlamına gelmektedir. ${ }^{2}$ Empati kelimesi içinde kavram olarak duygudan daha çok düşünme eylemini barındırmaktır. ${ }^{3}$ Bir kişinin empati becerisine sahip olması, o kişinin karşısındaki insanın duygularını anlayabilmesi ona göre gereken davranışı göstermesidir. ${ }^{3}$

Hekim hasta ilişkisinde hekimin bir empati becerisinin olması beklenen bir özelliktir. ${ }^{4}$ Empati becerisi, uygulamalı alanda çalışan hekimler için hastasıyla ilişki kurmasını ve onun acısını anlamasını sağlamaktadır. ${ }^{4}$ Hekim tarafından hastanın muayene edilip gözlenmesi ve şikayetlerinin dinlenmesi hastaya insan olarak değer verilmesini sağlar. ${ }^{4}$ Ancak ne yazık ki son zamanlarda teknolojinin artması, teşhis ve tedavi sürecinin kanıta dayalı tıbba ve somut delillere bağı olması, hekim hasta ilişkisinde empatinin varlığını azalttığı yönünde bir kaygı uyandırmaktadır. Yapılan çalışmalarda tıp fakültesi öğrencilerinin empati becerilerinde azalma olması ya da istenen düzeyde olmaması düşündürücüdür. Özellikle hekim adaylarının meslek eğitimlerinde empati becerisinin varlığının sorgulanması hekim hasta ilişkisi açısından önemsenmesi gereken bir durum olarak dikkati çekmektedir. ${ }^{4,5,6,7,8}$

Empati becerisi eğitim ile verilebilir, böylece hasta ile iletişimin iyileştirmesi sayesinde hastanın tedaviye uyumunu artırabilir; yapılan işten daha fazla memnun olunması sağlanabilir. $8,9,10,11,12$ Empati becerisinin ölçülmesi hekimin sahip olduğu beceriyi açığa çıkarması açısından önemlidir. Bu yeteneği ölçmeye yönelik birçok çalışma mevcuttur. ${ }^{7-15}$

Gelişen teknoloji ve bilgi artışının hekim hasta arasındaki ilişkiyi zedelediği ileri sürülebilir. ${ }^{16,17}$ Çağdaş hekimlik anlayışına sahip bir hekimde bütüncül yaklaşım ile hastanın tedavi sürecinin planlanması gerekir. Bütüncül yaklaşımda hekim sağlık sorunlarını bedensel, ruhsal/psikolojik, toplumsal/sosyal, kültürel ve varoluş boyutlarıyla ele alır. ${ }^{13}$ Hasta hekim arasındaki iletişim ve empati becerisi halen önemini korumaktadır. Bu bağlamda empati becerisinin bütüncül bir yaklaşım ile hekimin davranışını şekillendireceği düşünülebilir. Bu sayede hekim, karşısındaki insanın hastalığından dolayı çektiği acıyı, mağduriyeti hissedebilir, ona hoşgörü ile yaklaşabilir. ${ }^{4,18}$ Klinikte hasta bakan hekim her zaman hastasıyla birebir ilişkide bulunmaktadır. Yapılan çalışmaların sonuçları, klinikte çalışan hekimlerin uzmanlık alanlarıyla empati becerileri arasında farklılıklar olduğunu düşündürmektedir. ${ }^{12,15}$, Çocuk hastalıkları hekimlerinin, hastanın çocuk olmasından dolayı hem anne baba hem de çocuk ile ayrı ayrı birebir ilişki kurması gerekir. Dahili birimlerde görev yapan hekimler ile cerrahi birimlerde görev yapan hekimler arasında farklılıklar olduğunu ileri süren çalışmalar bulunmaktadır. ${ }^{12,15}$ Ancak literatürde çocuk sağlığı ve hastalıkları gibi birçok alt bilim dalını kapsayan özel çalışma bulunmamaktadır.

Bu çalışmanın amacı bir tıp fakültesi'nde çocuk sağlığı ve hastalıkları anabilim dalı'nda görev yapan hekimlerin empati becersini etkileyen olumlu ve olumsuz faktörleri belirlemektir.

\section{METHOD}

Bu çalışma Mersin Üniversitesi Tıp Fakültesi'nde, Çocuk Sağlığı ve Hastalıkları Anabilim Dalı'nda aktif olarak çalışan hekimler üzerinde yapıldı. 1-30 Temmuz 2018 tarihleri arasında 55 hekim üzerinde gönüllülük esasına dayanılarak yürütülmüştür. Veri toplama formu yüz yüze görüşme tekniği ile toplanmıştır. Veri toplama formu iki bölümden oluşmaktadır. Birinci bölümünde hekimlerin sosyodemografik özelliklerine yönelik 20 soruya yer verilmiştir. Sorular çalışmanın literatürüne göre yazarlar tarafından hekimlerin 
cinsiyeti, mezun oldukları okul, çalışma süresi, eğitimleri, sahip oldukları çocuk sayısı gibi hekimin empati becerisini etkileme olasılığı olan özelliklere göre belirlenmiştir.

Jefferson Empati Ölçeği, Jefferson Üniversitesi Tıp Fakültesi Tıp Eğitimi araştırma merkezinde doktor ve öğrencilerin empati becerisi düzeyini ölçme amacıyla geliştirilmiştir. ${ }^{13,14}$ ikinci bölümünde ise Jefferson Empati Skalasının Türkçe versiyonu kullanılmıştır. ${ }^{14}$ Yirmi maddeden oluşan "Jefferson Empati Ölçeği”nin 10 maddesi negatif, 10 maddesi de pozitif ifadeli cümlelerden oluşmuştur. Toplam alınan puan hesaplanmadan önce negatif ifadeli 10 maddenin $(1,3,6,7,8,11,12,14,18$, 19. maddeler) verileri ters çevrilmiştir. Böylece bu maddelerde 1= kesinlikle katılıyorum, 7= hiç katılmıyorum anlamında değerlendirilmiştir. En az 20 En yüksek 140 puan alınabilir. Katılımcı ne kadar yüksek puan alırsa o kadar yüksek empatik beceriye sahip demektir. Jefferson Empati Ölçeği üç faktörden oluşmaktadır. "Hastanın bakış açısını yakalama" adını alan birinci faktörde(F1) 10 madde, "sağlık hizmeti verirken duyarlı olma" adlı ikinci faktörde (F2) sekiz madde ve "hastayı anlama" olarak adlandırılan üçüncü faktör (F3) ise iki madde içermektedir. Üç faktörün toplam varyansı \%39.05; ölçegin tümüne iliskin Cronbach-Alpha iç tutarlık (güvenirlik) katsayısı ise 0.79 olduğu

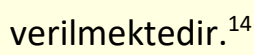

Değişkenlerin normal dağılıma uygun olup olmadıkları Shapiro Wilk testi ile incelenmiştir. Normal dağılım varsayımı sağlayan değişkenler ort $\pm s d$ cinsinden özetlenirken, varsayımı sağlamayan değişkenler medyan [25P.-75P.] (P.=Persentil) şeklinde özetlenmiştir. Kategorik değişkenler ise sayı ve yüzde cinsinden özetlenmiştir. İki grup karşılaştırmasında normal dağııı varsayımı sağlandığı durumda Independent Sample $t$ testi, varsayım sağlanmadığı durumda Mann Whitney $U$ testinden yararlanılmıştır. İiden fazla grup için normal dağılım varsayımı sağlandığı durumda ANOVA uygulanmış olup, farklılığın hangi gruplardan kaynaklandığını tespit etmek amacıyla Tukey testi, varsayım sağlanmadığı durumda ise Kruskal Wallis testi ve ardından Dunn testi yapılmıştır. İki sürekli değişken arasındaki ilişkiyi incelemek için Spearman korelasyon katsayısından yararlanılmıştır. $p<0,05$ istatistiksel anlamlıık düzeyi olarak kabul edilmiştir. Analizler Statistica 13.3.1 programında gerçekleştirilmiştir. Bu çalışma için Mersin Üniversitesi Sosyal ve Beşeri Bilimler Etik Kurulu'ndan onay alınmıştır.

\section{BULGULAR}

Çalışmaya Çocuk Sağlığı ve Hastalıkları Anabilim Dalı'nda görev yapan 65 hekimden 55'i dâhil edilmiştir. Araştırmaya katııım oranı çocuk sağlığı ve hastalıkları hekimleri için \%84,6'dır. Hasta yatak sayısı toplam 98 adettir. Katılımcıların \%47,3'ü kadın, \%52,7'si erkektir. Katılımcıların yaş ortalamaları 34,11 $\pm 6,99^{\prime}$ dur. Hekimlerin \%50,9'unun çocuğu yok, \%10,9'u profesör, \%56,4'ü uzmanlık öğrencisi, \%18,2'si yandal uzmanlık öğrencisidir. Hekimlerden 16,3'ü meslekte 20 yılın üzerinde çalışırken \%51'i mesleklerinin ilk on yılındadır. Hasta veya yakınından sözel şiddete uğrayan hekim oranı \%77,8 iken fiziksel şiddete uğrayanların oranı \%14,8'dir, hasta hekim ilişkisine yönelik eğitim alanların oranı \%36,4'dür (Tablo 1).

Katılımcıların ortalama Jefferson Empati Ölçeği puanı $98.42 \pm 12.71^{\prime}$ dür.

F2 ve toplam ortalama puan ile yaş arasında istatistiksel olarak zayıf, pozitif yönde ve anlamlı bir ilişki vardır $(r=0,364, p=0,007 ; r=0,361, p=0,011)$. F3 ile yaş arasında istatistiksel olarak zayıf, pozitif yönde ve anlamlı bir ilişki vardır $(r=0,331, p=0,015)$.

Hekimlerin deneyim yılı grupları arasında F1 değerleri bakımından istatistiksel olarak anlamlı bir fark yoktur $(p=0,054)$. Hekimlik deneyim yılı grupları arasında F2 değerleri bakımından istatistiksel olarak anlamlı bir fark vardır $(p=0,029)$. Bu farklıı̆ın kaynağını bulmak amacıyla post hoc testlerden Tukey testi sonucuna göre, 20 yıl üstü ve 10 yılın altı grupları arasında anlamlı bir fark tespit edilmiştir $(p=0,023)$. F3 değerleri bakımından da hekimlik deneyim yılı grupları arasında istatistiksel olarak anlamlı bir fark vardır $(p=0,014)$. 
Farklılığın kaynağını araştırmak amacıyla Dunn testi uyguladığımızda, 20 yıl üstü ve 10 yılın altı grupları arasında anlamlı bir fark tespit edilmiştir $(p=0,007)$.

Tablo1: Katılımcıların demografik özelliklerinin dağılımı

\begin{tabular}{lll}
\hline Demografik Bilgi & & Sayı (Yüzde) \\
\hline Unvan N(55) & Prof.Dr & $6(\% 10,9)$ \\
& Doç.Dr & $2(\% 3,6)$ \\
& Dr. Öğr. Üyesi & $5(\% 9,1)$ \\
& Yandal Uzmanı & $1(\% 1,8)$ \\
& Asistan Dr & $31(\% 56,4)$ \\
& Yandal Asist & $10(\% 18,2)$ \\
\hline Cinsiyet N(55) & Kadın & $26(\% 47,3)$ \\
& Erkek & $29(\% 52,7)$ \\
\hline Çocuk Varlığı N(55) & Var & $27(\% 49,1)$ \\
& Yok & $28(\% 50,9)$ \\
\hline Görev Yapılan Yıl Dağııımı N(23) & $10-20$ Yıl Arası & $9(\% 38,9)$ \\
& 20 Yıl Üstü & $3(\% 12,9)$ \\
& 10 Yıl Altı & $11(\% 47,3)$ \\
\hline Fiziksel Şiddet Varlığı N(54) & Evet & $8(\% 14,8)$ \\
& Hayır & $46(\% 85,2)$ \\
\hline Sözel Şiddet Varlığı N(54) & Evet & $42(\% 77,8)$ \\
& Hayır & $12(\% 22,2)$ \\
\hline Hasta- Hekim İlişkisi Eğitim N(55) & Evet & $20(\% 36,4)$ \\
& Hayır & $35(\% 63,6)$ \\
\hline Hekimlerin Deneyim Yılı N(55) & 20 Yııı̈ Üstü & $9(\% 16,3)$ \\
& $10-20$ Yıl Arası & $18(\% 32,6)$ \\
\hline \multirow{2}{*}{ Yaş N(55) } & 10 Yılın Altı & $29(\% 51)$ \\
\hline
\end{tabular}

Asistan eğitim süreleri açısından gruplar arasında toplam ortalama puan, F1, F2 ve $F 3$ değerleri bakımından istatistiksel olarak anlamlı bir fark yoktur $(p=0,562, p=0,511, p=0,606, p=0,621)$. Sözel şiddete uğrayan ve uğramayan grup arasında toplam ortalama puan, F1, F2 ve F3 değerleri bakımından istatistiksel olarak anlamlı bir farklılık yoktur $(p=0,480, p=0,327, p=0,875, p=0,965)$. Fiziksel şiddete uğrayan ve uğramayan grup arasında toplam ortalama puan, F1, F2 ve F3 değerleri bakımından istatistiksel olarak anlamlı bir farklılık yoktur $(p=0,727, p=0,783, p=0,743, p=0,425)$. Cinsiyetler açısından değerlendirildiğinde toplam puan ortalaması, F1, F2 ve F3değerleri bakımından kadın ve erkek grupları arasında istatistiksel olarak anlamlı bir fark bulunmadı $(p=0,776, p=0,695, p=0,931, p=0,192)$. Çocuğu olan ve olmayan grup arasında toplam puan ortalaması, F1 ve F2 değerleri bakımından istatistiksel olarak anlamlı bir fark saptanmadı $(p=0,088, p=0,119, p=0,214)$. Ancak $F 3$ değerleri bakımından çocuğu olan ve olmayan grup arasında istatistiksel olarak anlamlı bir fark vardır $(p=0,017)$ (Tablo2).

Yatak sayısı ile F3 değerleri arasında istatistiksel olarak zayıf, negatif yönlü ve anlamlı bir ilişki vardır ( $r=-$ $0,366, p=0,016)$. Çalışma koşulları ile F3 değerleri arasında istatistiksel olarak zayıf, anlamlı ve pozitif yönde bir ilişki vardır $(r=0,332, p=0,015)$ (Tablo3).

Tablo2: Jefferson Empati Ölçeği puanının cinsiyete ve çocuk sahipliğine göre dağılımı

\begin{tabular}{|c|c|c|c|c|c|c|c|}
\hline & Cinsiyet(N) & 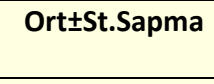 & $\mathbf{p}$ & & $\begin{array}{l}\text { Çocuk } \\
\text { Varlığı (N) }\end{array}$ & 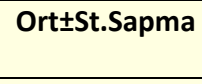 & p \\
\hline \multirow[t]{2}{*}{ Toplam } & Kadın N(23) & $97,86 \pm 11,93$ & 0,776 & Toplam & Var N(22) & $101,86 \pm 13,26$ & 0,088 \\
\hline & Erkek N(26) & $98,92 \pm 13,59$ & & & Yok N(27) & $95,62 \pm 11,76$ & \\
\hline \multirow[t]{2}{*}{ F1* } & Kadın N(24) & $46,29 \pm 5,61$ & 0,695 & F1* & $\operatorname{Var} \mathrm{N}(23)$ & $48,00 \pm 5,81$ & 0,119 \\
\hline & Erkek N(27) & $46,92 \pm 5,84$ & & & Yok N(28) & $45,50 \pm 5,42$ & \\
\hline \multirow[t]{3}{*}{$\mathrm{F}^{* *}$} & Kadın N(26) & $40,46 \pm 6,35$ & 0,931 & F2** & $\operatorname{Var} \mathrm{N}(27)$ & $41,62 \pm 7,42$ & 0,214 \\
\hline & Erkek N(28) & $40,28 \pm 8,37$ & & & Yok N(27) & $39,11 \pm 7,29$ & \\
\hline & & Median (Min-Ma & & & & Median (Min-M & \\
\hline \multirow[t]{2}{*}{$\mathrm{F} 3 * * *$} & Kadın N(25) & $12(8-14)$ & 0,192 & $\mathrm{~F} 3 * * *$ & Var N(25) & $13(8-14)$ & 0,017 \\
\hline & Erkek N(28) & $11(6-14)$ & & & Yok N(28) & $11(6-14)$ & \\
\hline
\end{tabular}

*F1: "Hastanın bakış açısını yakalama", **F2: "sağlık hizmeti verirken duyarlı olma", ***F3: "hastayı anlama" 
Tablo3: Çalışma koşullarına göre dağııımı

\begin{tabular}{ll}
\hline Çalışma Koşulları & $\begin{array}{l}\text { Ortalama } \pm \text { St. Sapma } \\
\text { Medyan[Min.-Max.] }\end{array}$ \\
\hline Yatak Sayısı & $38,73 \pm 36,72$ \\
& $22,50[3,00-97,00]$ \\
\hline Polikliniğe günlük başvuran hasta sayısı & $91,20 \pm 98,62$ \\
& $50,00[10,00-500,00]$ \\
\hline Günlük sizin poliklinikte muayene ettiğiniz hasta sayısı & $45,90 \pm 45,07$ \\
& $40,00[0,00-200,00]$ \\
\hline Çalışma koşullarınıza verdiğiniz puan & $5,24 \pm 2,32$ \\
& $5,00[1,00-10,00]$ \\
\hline Yataklı servis durumu & $\mathbf{N}(\%)$ \\
\hline & $54(98,2)$ \\
\hline
\end{tabular}

\section{TARTIŞMA}

Çağdaş hekimlik anlayışında hekimde empati kurma becerisinin varlığı, hem hastanın teşhis ve tedavi sürecini, hem de hasta hekim ilişkisini olumlu yönde etkilemesi muhtemeldir. Bu çalışma Çocuk Sağlığı ve Hastalıkları Anabilim Dalı'nda çalışan hekimlerin empati beceri düzeyini etkileyen faktörleri belirleme amacıyla yapılan bir pilot çalışmadır. Araştırmamıza katılan Çocuk Sağlığı ve Hastalıkları Anabilim Dalı'nda görev yapan hekimlerin toplam empati puanlarının ortalamaları 98,42 bulunmuştur. Çalışmamızda elde edilen puanların aynı ölçekle yapılan çalışmalardaki puanlara göre daha düşük olması dikkat çekicidir. ${ }^{8,14,20}$ Ancak hemşirelik mesleğinde yapılan çalışmada daha yüksek puan alınması, hemşirelik mesleğinde daha çok kadın olmasına, kadınların daha duygusal ve empati becerilerinin fazla olmasına bağlanabilir. ${ }^{21}$ Akgöz ve arkadaşlarının yaptığı çalışmada kadınlar daha fazla empatik beceriye sahiptir. ${ }^{19}$ Çalışmamızda ise cinsiyet açısından fark bulunmamıştır. Çalışmamızda elde edilen düşük puanın cinsiyete bağlı olduğu düşünülmemektedir.

Araştırmamızda hekimlerin yaşları ile empati becerisi arasında zayıf pozitif bir ilişki vardır. "Hastanın bakış açısını yakalama" ve "hastayı anlama" başlıkı iki faktör içinde yaş artıkça empati becerisinin arttığı saptandı. Benzer şekilde hekimlerin deneyim yılları artıkça özellikle 20 yılın üzerinde meslek hizmet süresi olanlar ile on yıldan daha az meslek süresi olanlar arasında fark olduğu saptandı. Hekimlerin deneyim süresi ve yaşları artıkça empati becerisinin artmasının nedeni olarak hekimin tecrübesinin hekim hasta ilişkisine olumlu yansıdığı düşünülebilir. Uludağ Üniversitesi'nde yapılan bir çalışmada da aynı şekilde yaş artıkça hekimlerin empati becerisinin arttığı saptanmıştır. ${ }^{19}$ Literatürde yaş ile empati becerisinin olumlu etkilendiğini ya da yaş ile ilişkili olmadığını bildiren çalışmalar bulunmaktadır. ${ }^{20,21,23}$

Çalışmamızda statü olarak daha yüksek olanların asistanlara göre istatistiksel olarak anlamlı olmasa da daha yüksek empati becerisine sahip olduğu bulunmuştur. Literatürde çalışma statüsü ile empati düzeyi arasında bir fark bulunmadığını bildiren çalışma mevcuttur. ${ }^{22}$ Statü artışı, yaş ve hekimlik deneyimi artışı zaman olarak farklı boyutlarda yer almakla birlikte birbirine koşut olarak değerlendirebilir. Bu bağlamda statüye ait görünen empati becerisindeki artma eğiliminin, yaş artışına bağlı olabileceği düşünülmektedir.

Çalışmamızda empati düzeyi açısından çocuk varlığı incelendiğinde; "hastayı anlama" olarak adlandırılan üçüncü faktörün çocuğu olanlarda daha yüksek olduğu tespit edildi. Bu faktör içinde "Hastalarım, onların duygularını anladığımda kendilerini daha iyi hissederler", "Tıbbi ya da cerrahi tedavide, empatinin tedavi edici önemli bir etken olduğuna inanıyorum" ifadeleri bulunmaktadır. Empati becerisinin sadece bir alt faktöründe fark olması çocuk sahibi olan hekimlerin çocuklar ile ilişkisinde, onları anlama konusunda daha fazla tecrübeye sahip oldukları düşünülebilir. Uludağ Üniversitesi'nde yapılan çalışmada da aynı şekilde çocuk varlığı empati düzeyini olumlu etkilemiştir. ${ }^{19}$ Ancak literatürde çocuk varlığı ile yokluğu arasında fark 
olmadığını ileri süren çalışmalar da mevcuttur. ${ }^{24}$ Empati kelimesinin anlamı "karşısındakini anlama" olarak kabul edildiğinde çocuğu olanlar çocukları anlıyor diyebiliriz.

Katılımcıların çalışma koşullarına verdikleri puan azaldıkça ve takip ettikleri yatak sayısı arttıkça empati becerilerinin azaldığı dikkati çekmektedir. Benzer şekilde literatürde, çalışma koşullarıyla ilgili memnuniyetsizlik artıkça empati puanlarının azaldığını gösteren çalışmalar mevcuttur. ${ }^{19,20,21}$ Yatak sayısı ya da polikliniğe başvuran hasta sayısı artıkça göreceli olarak hastaya ayrılan zamanın azaldığı bunun sonucunda bütüncül bakışı sağlamaya yönelik zamanın azaldığı ileri sürülebilir. ${ }^{17}$ Çalışma koşullarından duyulan memnuniyetin az olmasının, sadece takip edilen hasta sayısı ya da hekimin çalışma süresi fazlalığının sonucunda ortaya çıktığı düşünülemez. Çünkü çalışma koşullarını etkileyen bir durum olarak hekimlerin dörtte üçünün sözel, yüzde onunun fiziksel şiddete maruz kaldığını belirtmesi üzücüdür. Çalışmaya katılan hekimler, 2015 yılında aynı hastanede yapılan çalışmaya uyumlu bir şekilde fiziksel ve sözel şiddete maruz kaldıklarını belirtmişlerdir. ${ }^{8}$ Ayrıca katılımcıların yarısından fazlasının iletişim konusunda eğitim almadığını belirtmesi de önemlidir. Katııımcıların şiddete maruziyetleri ile iletişim konusunda eğitim alıp almamaları, empati beceri puanlarını etkilememektedir. Hekim hasta ilişkisinde hekimler herhangi bir eğitim almadıklarını belirtmiş olsalar da, tıp eğitimi müfredatının hekim hasta ilişkisine yönelik sosyal boyutu yürütebileceği donanımı sağladığı ileri sürülmektedir. ${ }^{7-8}$ Hekime tıp eğitimi boyunca klinik öncesinde kavramsal ve kuramsal alana yönelik eğitim verilirken, klinik dönemde ise klinik öncesi alınan bilgiler rol modellerle uygulamalı olarak somut hale dönüştürülmektedir. ${ }^{7,8}$ Ancak klinik dönemdeki eğitimin empati becerisi üzerine etkisi varsayılsa da 2007-2008 yılında yapılan çalışmada bu eğitimin bir katkısı olmadığı da iddia edilmektedir. ${ }^{7}$ Sağlık hizmeti sunumunda empati becerisi, ilişkinin temelini oluşturmaktadır. Hastaya empatik yaklaşım hastanın tedavi sürecini olumlu etkilemektedir. Eğitim becerisinin geliştirilmesini hedefleyen çalışma sayısı çok azdır. Empati becerisi düşük olan öğrencilere empati becerisini artırmaya yönelik bir çalışmada on haftalık başka bir çalışmada on üç haftalık eğitim verilmesiyle öğrencilerin empati becerisinin anlamlı olarak arttığı saptanmıştır. ${ }^{26,27}$ Yapılan çalışmalarda doğrudan bir eğitim olmadığında empati beceri puanlarında fark bulunmaması empati becerisine yönelik özel bir eğitimin zorunluluğuna işaret etmektedir diye düşünülebilir.

Araştırmamızın az sayıda katılımcı ile yapılması çalışmanın kısıtııı̆ı olarak değerlendirilebilir. Ancak sağlık hizmeti sunumunda klinik öncesi ve klinikte hasta başı eğitimde empati becerisi hakkında literatüre uyumlu sonuç elde edilmiştir. Sağılı hizmeti sunumunda çağdaş anlayış ve bütüncül yaklaşım ile hizmet veren hekimlerde, hekim hasta iletişiminde empati becerisinin istenen seviyede olması sadece rol model hekimlerin çabası ile mümkün olmayacağı düşünülmektedir. Bu amaçla empati becerisi eğitimi verilmesi önemlidir. Ancak empati becerisi eğitimine yönelik eğitimin planlanması içeriğinin geliştirilmesi gerekmektedir. Bu pilot çalışma bu amaca yönelik tanımlayıcı bir şekilde çocuk sağlığı ve hastalıkları hekimlerinin empati becerisini etkileyen faktörleri açığa çıkarmıştır. Bu araştırma sonucunda elde edilecek veriler çocuk sağlığı ve hastalıkları uzmanlarının geneline yönelik empati becersini etkileyen faktörleri ortaya çıkarmaya yönelik çalışmada kullanılacaktır.

Sonuç olarak hekim-hasta ilişkisinde empati becerilerini araştırdığımız pilot çalışmada katılımcıların toplam puanlarının ortalamanın üzerinde olmasının pozitif bir durum olmasına rağmen literatürdeki hekimlere yönelik puanlardan daha düşük olması düşündürücüdür. Bu pilot çalışmanın uygulanması sırasında elde edilen verilere dayanarak, empati becerilerini etkili bir şekilde etkileyen faktörlerde olumlu yönleri güçlendirecek çalışmaları geliştirmek hedeflenmelidir. Bu hedefe ulaşmak için asistan hekimlerin empati becerisi eğitiminin sağlanması, hasta başında denetlenmeleri olumlu tutum ve davranışları pekiştirilmesi, değişimleri sağlayacak eğitim programlarının planlanması ile mümkün olacaktır. 


\section{BILGi}

Çalışma 04/10/2018- 06/10/2018 tarihlerinde İstanbul, Türkiye'de düzenlenen "The 5th International and Interdisciplinary Conference on. Health, Culture and the Human Body Principles of Biomedical Ethics, Genetics and Human Enhancement" da sözlü bildiri olarak sunulmuştur.

\section{KAYNAKLAR}

1. Türk Dil Kurumu. Erişim Adresi: http://tdk.gov.tr/

2. Barnes A, Thagard P. Empathy and analogy. Erişim Adresi: http://cogsci.uwaterloo.ca/Articles/Pages/Empathy.html

3. Chismar D. Empathy and sympathy: the important difference. The Journal of Value Inquiry 1988;22:257-266. Erişim Adresi: https://link.springer.com/content/pdf/10.1007/BF00136928.pdf

4. Spiro H. Commentary: the practice of empathy. Acad Med September 2009;84(9):1177-1179.

5. Hojat $\mathrm{M}$, et al. The devil is in the third year: A longitudinal study of erosion in empathy in medical school. Acad Med 2009;84:1182-1191. Erişim Adresi: Ovid Full Text Bibliographic Links [Context Link]

6. Bikgel N. Özçakır A. Jefferson empati psikometrik özelliklerinin Türkçe versiyonu. European Scientific Journal (ESJ) Temmuz 2017;13(20). DOI:10,19044 / esj.2017.v13n20p101

7. Kadığlu S. ve ark. Tıp Fakültesi öğrencilerinin klinik eğitimin empati becerisi üzerine etkisi. İnönü Üniversitesi Tıp Fakültesi Dergisi 2011;18(1):33-37.

8. Ögenler O, Yapıcı G., Uzel İ. Tıp fakültesi öğrencilerinin empati becerileri hakkında görüşleri. In Işı Ülman Y, Artvinli $F$, editors. Değişen Dünyada Biyoetik. İstanbul: Türkiye Biyoetik Derneği Yayını; 2012.Pp:318-325. (Tbd VII. Kongresi, İstanbul 12-13 Ekim 2012).

9. Artıran Ĭğde F, Şahin MK. Changes in empathy during medical education: an example from Turkey. Pak J Med Sci 2017 SepOct;33(5):1177-1181. doi:10.12669/pjms.335.13074

10. Çam O. Hemşirelik Yüksekokulu öğrencilerinde psikodramanın empatik eğilim ve empatik beceri üzerine etkisi. Ege Üniversitesi Hemşirelik Yüksekokulu Dergisi 1995;11:55-63.

11. Hojat $\mathrm{M}$, et al. The Jefferson Scale of Physician Empathy: further psychometric data and differences by gender and specialty at item level. Acad Med 2002;77(10 Suppl):58-60.

12. Avasarala S. K, Whitehouse S, Drake S M. Internship and empathy: variations across time and specialties. Southern Medical Journal 2015;108(10):591-595.

13. Hojat $M$, et al. The Jefferson Scale of Physician Empathy: development and preliminary psychometric data.Educ Psychol Meas 2001;61:349-365.

14. Gönüllü í. Ankara Üniversitesi Tıp Fakültesi'nde paralel yürütülen farklı eğitim sistemleriyle öğrenim gören dönem 5 öğrencilerinin "empati" beceri düzeyleri, Yüksek Lisans Tezi, Ankara Üniversitesi Sağlık Bilimleri Enstitüsü Tıp Eğitimi ve Bilişimi Ana Bilim Dalı Ankara, 2007.

15. Hojat M, et al. Empathy in medical education and patient care. Acad Med 2001;76:669.

16. Hojat $\mathrm{M}$, et al. Physician empathy in medical education and practice: Experience with the Jefferson scale of physician empathy. Seminars in Integrative Medicine 2003;1:25-41.

17. Şahin G., Artıran İğde Füsun A. Hasta merkezli bakım-ortak karar alma süreci ve kalite. Türkiye Klinikleri J Fam Med-Special Topics 2014;5(3):38-43.

18. Teke A. K., Cengiz E., Demir C. Hekimlerin empatik özelliklerinin ölçümü ve bu ölçümlerin demografik değişkenlere göre değişimi. Ç.Ü. Sosyal Bilimler Enstitüsü Dergisi 2010;19(3):505-516.

19. Akgöz S. ve ark. Uludağ Üniversitesi Sağlık Uygulama ve Araştırma Merkezi'nde çalışan hekimlerin empatik eğilimleri. Turkiye Klinikleri J Med Ethics 2005;13:97-104.

20. Şahin S. ve ark. Bir hastanede çalışan hemşirelerin empati ve tükenmişlik düzeylerinin değerlendirilmesi. Konuralp Tıp Dergisi 2018;10(3):318-325.

21. Şen H. ve ark. Birinci basamak sağlık hizmetlerinde görev yapan sağlık çalışanlarının empatik beceri düzeyleri. Psikiyatri Hemşireliği Dergisi 2012;3(1):6-12.

22. Kılıç T, Seymen O. Sağlık sektöründe tükenmişlik sendromuna etki eden faktörlerin analizi ve bir araştırma. Yönetim ve Ekonomi Araştırmaları Dergisi 2011;16:47-67.

23. Kumcağız H. ve ark. Hemşirelerin iletişim becerileri: Samsun ili örneği. Dicle Tıp Dergisi 2011;38:49-56.

24. Taşdemir G. Ege Üniversitesi Uygulama ve Araştırma Hastanesi'nde çalışan hemşirelerin empatik eğilim ve iş doyum düzeyleri arasındaki ilişkinin incelenmesi. Ege Üniversitesi Sağlık Bilimleri Enstitüsü Yüksek Lisans Tezi, 1999.

25. Ögenler O, Yapıcı G. Assessment of physical violence against research assistants and nurses in an university hospital. Acta Bioethica 2018;24(1):19-29. 
26. Bilge Y, Bilge Y. Empati eğitim programının empatik eğilim düzeyi üzerindeki etkisinin incelenmesi: sağlık meslek lisesi örneği. Uluslararası Sosyal Araştırmalar Dergisi 2017;10(52):607-614.

27. Karaca A, Açıkgöz F, Akkuş D. Eğitim ile empatik beceri ve empatik eğilim geliştirilebilir mi?: bir sağlık yüksekokulu örneği. ACU Sağlık Bil Derg 2013;(4):118-122. 